\title{
CONSTRUCCIÓN DE UNA PRAXIS INSTITUCIONAL EN EL PERÚ DEL SIGLO XVI: LA VOLUNTARIEDAD DE LOS DONATIVOS
}

\author{
CONSTRUCTION OF AN INSTITUTIONAL PRAXIS IN PERU \\ OF THE XVI CENTURY: THE VOLUNTEERING OF THE GIFTS
}

\author{
Loris de Nardi*
}

\begin{abstract}
Los Austrias solicitaron en el virreinato del Perú veinte donativos, los que permitieron recaudar por lo menos 7.487.935 pesos. Sin embargo, a la fecha, no mucho se sabe al respecto, ya que la historiografía solo recientemente ha empezado a centrarse en esta herramienta de recaudación extraordinaria. La investigación que se presenta se propone por lo tanto empezar a colmar esta laguna, mediante el examen de las muchísimas fuentes éditas publicadas durante los siglos XIX y XX. El recurso a esta variada documentación permitirá cuantificar con más precisión los donativos solicitados; definir las diligencias puestas en acto por los agentes involucrados en su recolección; entender la cultura política y jurídica que legitimó su recaudación; poner en tela de juicio la creencia errónea, pero aún a menudo considerada legítima por la historiografía, por derivarse de la experiencia coeva castellana, que califica como servicios forzosos los donativos voluntarios pedidos por los Habsburgo de España en las Indias, en general, y en Perú, en particular.
\end{abstract}

Palabras claves: Monarquía católica, donativos voluntarios, Austrias mayores, virreinato del Perú, siglo XVI.

The Austrias requested twenty voluntary gifts from the viceroyalty of Peru, which allowed them to collect at least 7,487,935 pesos. However, to date, not much is known about it, and only in recent times has historiography begun to focus on this collection tool. This article aims to begin to fill this gap, by examining the many edited sources published during the 19th and 20th centuries. Using this varied documentation will allow quantifying with more precision the gifts requested; to define the procedures implemented by the agents involved in its collection; to understand the political and legal culture that legitimized the collection of the voluntary gifts; to deny the erroneous belief, nonetheless, still often considered legitimate by historiography, as it derives from the Castilian experience, which qualifies as forced services the voluntary gifts requested by the Habsburgs of Spain in the American territories, in general, and in the viceroyalty of Perú, in particular.

Key words: Catholic Monarchy, Voluntary Gifts, Mayor Austrias, Viceroyalty of Peru, XVI century.

\section{Introducción}

El presente artículo quiere proporcionar una panorámica de los donativos voluntarios pedidos por los Habsburgo en el virreinato del Perú durante el siglo XVI, para subrayar que en las Indias la recolección de estos servicios nunca tuvo un carácter forzoso, analizando la cultura política y jurídica que legitimó recurrir a esta medida extraordinaria. Será así posible poner sobre la mesa una temática a menudo olvidada por la historiografía. De hecho, si es irrefutable que solo hace algunos años los historiadores han empezado a centrarse en los donativos pedidos en las Indias durante los siglos XVI e XVII ${ }^{1}$, resulta aún más evidente que todavía se sabe muy poco sobre ellos, y, aún menos, respecto de los solicitados en los territorios peruanos por los Austrias mayores ${ }^{2}$. Además, el estudio llevado a cabo permitirá poner en tela de juicio la creencia errónea, pero aún a menudo considerada legítima por la historiografía, por derivarse de la experiencia coeva castellana ${ }^{3}$, que califica los donativos voluntarios pedidos en las Indias por los Habsburgo como servicios forzosos ${ }^{4}$. Por estas razones, antes de profundizar en los donativos voluntarios solicitados por la Corona a los vasallos peruanos a lo largo del siglo XVI, se presentará sintéticamente lo que hasta la fecha se pudo averiguar respecto del tema, como también la actualización de la cuestión que permitió llevar a cabo la presente investigación.

\footnotetext{
* Centro de Estudios Históricos, Universidad Bernardo O’Higgins; Colaborador Externo de la Universidad de Navarra ICS, Creativity and Cultural Heritage. Dirección postal: Limache 1270. Viña del Mar, Chile.

Correo electrónico: lorisdenardi@gmail.com
} 


\section{Periodización y principales características de los donativos voluntarios solicitados por los Habsburgo a los vasallos indianos}

Los donativos en las Indias fueron solicitados por la Corona ya durante el reinado de los Reyes Católicos. En 15015, "porque las necesidades de sus altezas eran muy grandes, con las guerras que a la sazón se ofrecían contra los Turcos", Fernando e Isabela encargaron a Nicolás de Ovando, por entonces gobernador de la isla La Española, que "procurase que se hiciese un servicio voluntario, prometiendo su palabra real, que cumplirían todo lo que para ello se tuviera que prometer" (Herrera y Tordesillas 1730: Década I:Libro IV:118) ${ }^{6}$. En 1506, Fernando el Católico, buscando resanar las cajas reales, encargó a Cristóbal Rodríguez, que en aquel entonces se encontraba en la corte y se reputaba muy experto en el idioma de los indígenas de la isla La Española, de "tratar con ellos, para que hiciesen algún servicio a la Corona" (Herrera y Tordesillas 1730:Década I:Libro VI:169).

La práctica no mermó con los Austrias, quienes, en casi 180 años, solicitaron veinticuatro donativos voluntarios a los vasallos indianos ${ }^{7}$. A lo largo de su reinado, Carlos $\mathrm{V}$ pidió en las Indias tres donativos: en 1520 en la isla La Española ${ }^{8}$, en 1532 en los territorios novohispanos (Ciaramitaro e De Nardi 2020:524-525; De Nardi 2018b:1159) y en 1534 en los territorios peruanos 9 . Bajo el gobierno de Felipe II, recurrir a esta medida extraordinaria de recaudación se institucionalizó: la Corona solicitó tres veces los donativos, en $1556^{10}, 1574^{11}$ y 1589 , solicitándolos de manera más o menos simultánea en ambos virreinatos americanos ${ }^{12}$. Durante los reinados de los Austrias menores, la práctica llegó a asumir finalmente un carácter sistémico: dos donativos fueron solicitados por Felipe III (1598 y $\left.1609^{13}\right)$; ocho por Felipe IV $\left(1621,1625^{14}, 1631\right.$, 1636, 1640, 1647, 1654, 1660); ocho por Carlos II $\left(1665,1672,1678,1679,1684^{15}, 1688,1689,1697\right)$. En resumen, desde la mitad del siglo XV hasta el final del sucesivo, en media, la Corona pidió en sus virreinatos indianos un servicio gracioso cada cinco años (De Nardi 2018a:12-17).

La casi totalidad de los donativos fueron generales, es decir, la solicitud de la Corona se dirigió a toda la población ${ }^{16}$, y hasta la década de los treinta del siglo XVII los vasallos pudieron elegir si socorrer al soberano con donaciones o préstamos ${ }^{17}$. Además, las donaciones no tenían que ser precisamente en dinero, sino que podían entregarse metales (oro, plata, plomo), joyas, artefactos preciados, productos agrícolas y unidades de ganado $^{18}$. Las investigaciones acerca del tema incluso permitieron averiguar que los principales contribuyentes en los donativos de los siglos XVI y XVII siempre fueron individuos que tenían algún interés en el regio patronato (ministros y oficiales reales, militares, eclesiásticos, rentistas, mineros), cuya decisión de socorrer al soberano siempre fue libre, ya que los donativos mantuvieron durante toda la época de los Habsburgo un doble carácter voluntario: "los ministros y oficiales podían decidir si pedir el servicio en su jurisdicción; los vasallos eran libres de no contribuir" (De Nardi 2018b:15911592). De hecho, la recaudación de los servicios se fundaba principalmente en la construcción de un amplio consenso alrededor de la petición soberana, para ello los oficiales reales encargados del delicado asunto estaban acostumbrados a poner en marcha una campaña de sensibilización, basada en argumentaciones persuasivas y en la emulación que ellos mismos debían suscitar en su respectiva jurisdicción, contribuyendo personalmente (De Nardi 2018b:1591-1592).

\section{Cuantificación de los donativos solicitados por los Austrias a los vasallos peruanos}

La cuantificación de lo recolectado en las Indias por los Habsburgo de España gracias a los donativos resultaba aún parcial al momento de realizar esta investigación: el monto calculado por el virreinato de la Nueva España ascendía a tan solo 521.064 pesos y por aquello del Perú a 242.877 pesos. Es decir, se estimaba que a lo largo de 180 años el recurso de los donativos permitió reunir en los dos virreinatos apenas 763.941 pesos; una suma demasiado pequeña si se considera el mucho tiempo, trabajo y compromiso, tanto personal como económico, que la recaudación de estos servicios requería a los oficiales reales. Piénsese que para cada donativo el virrey tenía que "llamar a las personas de plaza al Palacio, proponiéndoles la necesidad de su Magestad, con amigables palabras sacar buenamente de cada uno lo que llegan a ofrecer conforme sus caudales". Luego, debía hacerse lo mismo con los demás individuos, enviando los oidores y demás ministros de la Real Audiencia, "por ser personas de autoridad y respeto", y las más capaces de "moverse con eficacia para persuadir con discreción", a pedir el 
socorro "por barrios y calles, casa en casa" (Escalona 1775:109). En fin, lo mismo tenía que hacerse en las demás provincias y ciudades del virreinato: la comisión se encargaba a los respectivos gobiernos y reales audiencias, donde los oidores estaban acostumbrados a escribir y viajar a todas las ciudades para sensibilizar a los miembros del cabildo con el fin de desarrollar en su jurisdicción una campaña de persuasión y recaudación (De Nardi 2020; De Nardi 2018b; Escalona 1775:109).

Consideradas las grandes e importantes diligencias que los ministros tenían que llevar a cabo para poder recaudar el donativo, era lógico imaginar entonces que los montos tuvieran que ser mucho más conspicuos, porque de otra manera no se entendería el continuo recurso a esta medida de recaudación extraordinaria. Entonces, el tema se demuestra de primaria importancia, ya que cuantificar con más precisión estas sumas permitiría entender mejor la relevancia que el recurso a este arbitrio tuvo en la política indiana de los Habsburgo de España. Por esta razón, para empezar a colmar la laguna, se llevó a cabo una pesquisa centrada en las muchísimas fuentes editadas durante los siglos XIX y XX, que permitió definir con más precisión las fechas de los varios donativos pedidos por los Habsburgo en el virreinato del Perú; determinar que estos servicios efectivamente fueron veinte $(1534,1574$, 1589, 1598, 1621, 1626, 1631, 1636, 1640, 1647, $1654,1660,1665,1672,1678,1679,1684,1688$, $1689,1697)^{19}$; cuantificar en 7.487 .935 pesos el monto total recolectado solo en el virreinato del Perú gracias a esta herramienta de recaudación extraordinaria: un importe casi treinta y una veces superior a lo que se había estimado en un primer momento (Tabla 1).

Tabla 1. Actualización de las fechas y montos de los donativos voluntarios recaudados por los Habsburgo en el virreinato del Perú ${ }^{20}$

\begin{tabular}{|c|c|c|c|}
\hline Fecha anterior & Monto anterior & Fecha & Monto \\
\hline 1534 & $\$-$ & 1534 & $\$ 34,513.00$ \\
\hline 1575 & $\$-$ & 1574 & $\$ 401,970.00$ \\
\hline 1589 & $\$ 2,551.00$ & 1589 & $\$ 2,143,773.00$ \\
\hline 1598 & $\$-$ & 1598 & $\$ 610,000.00$ \\
\hline 1621 & $\$ 150,000.00$ & 1621 & $\$ 283,000.00$ \\
\hline 1626 & $\$-$ & 1625 & $\$ 530,363.00$ \\
\hline 1631 & $\$ 27,616.00$ & 1631 & $\$ 443,616.00$ \\
\hline 1636 & $\$ 23,021.00$ & 1636 & $\$ 33,521.00$ \\
\hline 1640 & $\$-$ & 1640 & $\$ 350,000.00$ \\
\hline 1647 & $\$-$ & 1647 & $\$-$ \\
\hline 1654 & $\$ 10,000.00$ & 1654 & $\$ 178,380.00$ \\
\hline 1660 & $\$ 4,440.00$ & 1660 & $\$ 4,440.00$ \\
\hline 1665 & $\$-$ & 1665 & $\$-$ \\
\hline 1672 & $\$-$ & 1672 & $\$ 88,793.00$ \\
\hline 1678 & $\$-$ & 1678 & $\$ 2,164,080.00$ \\
\hline 1679 & $\$-$ & 1679 & $\$ 135,540.00$ \\
\hline 1684 & $\$-$ & 1684 & $\$ 2,000.00$ \\
\hline 1688 & $\$-$ & 1688 & $\$ 23,497.00$ \\
\hline 1689 & $\$ 25,249.00$ & 1689 & $\$ 26,249.00$ \\
\hline \multirow[t]{2}{*}{1697} & $\$-$ & 1697 & $\$ 34,200.00$ \\
\hline & $\$ 242,877.00$ & & $\$ 7,487,935.00$ \\
\hline
\end{tabular}




\section{Construcción de una praxis institucional en el Perú del siglo XVI: la voluntariedad de los donativos}

El primer donativo voluntario a los vasallos peruanos fue solicitado por Carlos I, quien, en 1534, encargó su recaudación a Hernando Pizarro, mientras se encontraba en Castilla para entregarle el quinto real del rescate pedido a los incas por la liberación de Atahualpa. Según la versión oficial, el emperador, al enterarse de lo que había pasado en aquellas lejanas tierras, no se demostró muy conforme con el hecho que el rescate se había repartido entre los conquistadores de Cuzco: pensaba que por ser de persona principal habría debido correspondérsele, por completo. Así que decidió encargar a Hernando Pizarro la recaudación de un servicio gracioso, justificando la petición con el argumento que si bien habría sido su derecho de rey reclamar la entrega del entero monto, había optado por no hacerlo.

Sin embargo, algunos elementos permiten pensar que con toda probabilidad Carlos I ya tenía planeado pedir un donativo a los vasallos peruanos y solo aprovechó la oportunidad que le proporcionó el viaje de Hernando Pizarro a España. De hecho, en 1520, siguiendo el ejemplo de sus abuelos, Carlos había intentado pedir un primer donativo en La Española (Herrera y Tordesillas 1730:Década II:Libro IX:225). En noviembre del 1532, Isabela de Portugal había despachado una cédula a la Audiencia de Nueva España para solicitar en aquel virreinato un donativo en socorro de las cajas imperiales agotadas por la guerra contra los turcos (Ciaramitaro e De Nardi 2020:524-525; De Nardi 2018b:1159).

A diferencia de los Reyes Católicos, quienes "prometiendo su palabra real, que cumplirían todo lo que para ello se tuviera que prometer" (Herrera y Tordesillas 1730:Década I:Libro IV:118), Carlos nunca se comprometió a nada al momento de solicitar un donativo. Hasta un principio, los servicios solicitados se configuraron, por tanto, como gratuitos: los vasallos tenían que socorrerlo, si quisieran, sin pedir nada a cambio. De hecho, en la cédula de 1532, la emperadora se limitó a decir que los que aceptaran socorrer al emperador habrían sido bien visto a sus ojos, sin añadir nada más comprometedor; en cambio, fue muy cautelosa en precisar que el servicio solicitado habría tenido que ser personal, ya que quedaba prohibido que los encomenderos ofrecieran sumas recolectadas entre los indios puestos bajo su protección, y voluntario, por ordenarse expresamente a los ministros,

tenerles (los vecinos) en buena gobernación y disponerse lo mejor que pudiese para visitarlos y otras cosas que os parezca convenibles y para ellos agradables y podáis ser ciertos que nuestra voluntad no es de ponerles imposición sino socorro por esta vez para esta gran necesidad a que de su propia voluntad en estos nuestros reinos todos nos ayudan con personas y haciendas como son obligados. Así habéis de estar advertidos que se ha de tener tal forma que muy de su voluntad nos ayuden [...] (De Nardi 2018b:1559).

Claramente, en 1532 no habría sido posible enviar la misma cédula a Perú: el proceso de conquista se encontraba aún en una fase embrionaria y no existía una administración que pudiera encargarse del asunto $^{21}$. Sin embargo, las numerosas y fabulosas noticias que ya habían llegado de aquellas lejanas tierras debieron convencer a la Corona a esperar el momento propicio para solicitar un donativo voluntario también a los conquistadores peruanos, como ya se había hecho con los caribeños y mexicanos $^{22}$. Oportunidad que se presentó con la llegada del hermano de Francisco Pizarro a España, quien regresó a Perú durante el primer tercio de 1535 con la misión de recaudar un donativo voluntario en socorro de las exhaustas cajas de la Corona, pudiendo contar también con " 37 cédulas en blanco para las personas que les pareciese" (Colección de Documentos 1924:XV:114) ${ }^{23}$. Lamentablemente estos documentos todavía no se han podido recuperar, así que no fue posible reconstruir con exactitud las argumentaciones persuasivas utilizadas por la Corona al momento de solicitar el donativo. Sin embargo, cruzando varias informaciones al respecto, se pueden avanzar algunas hipótesis. Muy probablemente, Carlos V en las cédulas entregadas a Pizarro debió exponer la difícil coyuntura militar que estaba enfrentando, para poder subrayar que las guerras que se veía obligado a combatir eran necesarias para la defensa de la fe y el bienestar de todos sus vasallos, incluidos los que estaban en las Indias; que su titánica empresa tenía costes elevados, que sus arcas estaban vacías y que por esto necesitaba lo más pronto posible el socorro de sus fieles vasallos peruanos; aún más, considerando 
que si bien el rescate de Atahualpa habría debido entregarse a él por completo, porque le correspondía por derecho de realeza, había decidido no reclamarlo y quedarse con solo el quinto que se le había enviado. En fin, es muy probable que el emperador sugiriera a los destinatarios de las cédulas que suscitaran emulación entre sus aliados y clientes, donando ellos mismos en primera persona. Lo dicho puede deducirse por las argumentaciones persuasivas utilizadas por Hernando Pizarro al momento de solicitar el donativo y por algunos pasajes de una carta que Francisco Pizarro escribió al emperador. De hecho, una vez regresado a Perú, Hernando, "ansioso de cumplir las promesas que había hecho en la corte", empezó a hostigar a los españoles que se encontraban en Lima "para que hiciesen al rey un servicio extraordinario y le ayudasen a hacer frente a los enemigos y guerras que tenía en Europa" (Quintana y Lorenzo 1922:III:169). Sus argumentos, sin embargo, no debieron bastar para suscitar el entusiasmo esperado, porque la mayoría de los entrevistados se negó a contribuir:

decían que bastante hacían por el Rey en enviarle aquellos grandes quintos que de ellos recibía, ganados a fuerza de sudor, de trabajos y de sangre, sin que el Rey de su parte les hubiese ayudado con nada para ello; que no querían contribuir más con sus haciendas para que él [Hernando Pizarro] y su hermano solos fuesen los agraciados por el Rey (Quintana y Lorenzo 1922:III:169).

Muy pronto pareció claro que el donativo corría el riesgo de naufragar porque la mayoría de los conquistadores no confiaba en Hernando, acusado de haber viajado a España solo para defender sus intereses, los de su hermano Francisco y de su amigo, Diego de Almagro. De hecho, decían, había logrado conseguir solo el hábito de Santiago para él, el marquesado para su hermano, y el título de adelantado para Almagro (Quintana y Lorenzo 1922:III:169). Todos los demás, por el contrario, no solo no habían recibido ninguno de los honores y mercedes, que evidentemente los dos hermanos les habían prometido, sino que se veían solicitados a contribuir una vez más con su propia hacienda a las guerras del emperador (Quintana y Lorenzo 1922:III:169-170). Y si esto no fuera suficiente, Hernando de su parte no hacía nada para intentar reconciliar los ánimos: para convencer a sus compatriotas, en vez de recurrir a medios suaves y persuasivos, "los amenazaba con que les haría restituir el rescate de Atahualpa, el cual por ser del rey pertenecía al rey; y abandonándose a su genio arrogante y orgulloso, los tachaba de ingratos y hombres viles, que no merecían la fortuna que tenían" (Quintana y Lorenzo 1922:III:169-170). La situación se hizo tan tensa que tuvo que intervenir Francisco Pizarro, quien defendió a los demás de los insultos de su hermano e intentó recolectar algo de donativo, dirigiéndose a sus compañeros de conquista, diciéndoles que

merecían tanto como los que asistieron a don Pelayo en la restauración de España, añadiendo que la lealtad castellana no se ponía nunca a controvertir servicios con su príncipe, les pidió que se la mostrasen con generosidad en la ocasión presente, dándoles de paso la esperanza de que tal vez le concedería a perpetuidad los indios que hasta entonces no tenían más que en depósito (Quintana y Lorenzo 1922: III:170).

Es decir, Francisco les hizo entender que socorrer graciosamente el soberano les proporcionaría en futuro la posibilidad de pedir algo a cambio, como por ejemplo, la deseada perpetuidad de las encomiendas. Y el punto debió convencer a la mayoría porque parece que los principales conquistadores limeños aceptaron socorrer al soberano, a pesar de que no sabemos todavía exactamente el número de los donantes y el monto exacto de los aportes. En Cuzco las cosas no debieron ser diferentes: los españoles si en un primer momento se resistieron a donar, al final aceptaron hacerlo. De hecho, en noviembre de 1535, Francisco Pizarro escribió a Carlos V para ponerle al tanto que en Cuzco el servicio voluntario no parecía poder tener el éxito esperado (Alarcón Olivos 2017:159; Del Carmen Martín Rubio 2014:319; Lohmann Villena 1986:4647), y esto no obstante que él mismo había puesto la parte más cuantiosa de lo que por entonces se había recaudado. En cambio, en marzo del año sucesivo, 57 vasallos habían decidido socorrer al soberano con sus propios caudales, por un monto total de 34.513 pesos, 1 ducado de oro y 1.446 marcos de plata de medio (Rojo Vega 2007:488): un monto para nada despreciable si se considera que solo la parte en pesos del donativo equivalía a 9.387.536 maravedís, es decir, mitad de la renta anual del 
duque de Medina Sidonia, uno de los principales magnates sevillanos de la época (Montoya 2013:47).

Muy probablemente el cambio de rumbo se debió al hecho que los Pizarro debieron recurrir a la coerción para incrementar el monto recaudado, $\mathrm{o}$, por lo menos, ejercer presiones indebidas sobre algunos de los donantes para empujarlos a colaborar. De hecho, en el documento que contiene el listado de los contribuyentes y el monto recolectado se menciona que Francisco Pizarro, una vez enviado el donativo a España, informó al soberano que "algunos de los que contribuyeron en el dicho servicio ha[bía]n intentado e intentan cobrar de lo que por su propria voluntad dieron y sobre ello se han movido y se mueven pleitos" (Rojo Vega 2007:488). Claramente, los individuos que querrían recuperar el dinero no debieron pensar en ningún momento que las donaciones habían sido voluntarias, y cuando sus quejas llegaron a la corte se convirtieron en un problema bastante importante para Carlos V, quien desde el principio al respecto debió haber sido muy claro: el donativo habría tenido que ser voluntario como muy claramente lo había subrayado en la cédula enviada solo pocos años antes en Nueva España. $\mathrm{Y}$ esto por un motivo muy preciso: la Corona, por medio de los donativos, intentaba recaudar dinero para financiar la política imperial sin deteriorar ulteriormente la ya turbulenta relación con los conquistadores (Bakewell 1989), y, sobre todo, sin tener que pagar un "gasto político". Es decir, tener que conceder mercedes o prerrogativas jurisdiccionales, de matriz feudal, a cambio del apoyo proporcionado. De hecho, la voluntariedad del servicio conllevaba su gratuidad, por la que los socorredores peruanos del soberano no habrían podido pedirle nada a cambio de inmediato, ya que las donaciones por ser voluntarias terminaban por configurarse como un reconocimiento de los grandes sacrificios que la Corona diariamente tenía que enfrentar en defensa de la religión, el bienestar y la paz común. Así que su participación voluntaria en el servicio no los ponía en condición de negociar, sino que cancelaba la deuda feudal, política y moral que tenían con el soberano. En otras palabras, los donativos, siempre y cuando voluntarios, permitían, por tanto, a la Corona pedir a los conquistadores peruanos que contribuyeran a la política imperial sin tener que recompensarlos. Un detalle no secundario, si se considera que si bien los conquistadores quisieran ver premiados sus esfuerzos con la concesión de prerrogativas feudales, la Corona nunca tuvo las intenciones de concedérselas, por no confiar en ellos y por no querer que en los territorios americanos se constituyeran cuerpos antagonistas, parecidos a la nobleza y ciudades castellanas, que, en los mismos años, mediante la revuelta de los comuneros y de las asambleas estamentales, muchos problemas estaban creando a Carlos V (Ciaramitaro e De Nardi 2019:20; Bartolmé Yun 2015:37)24. De hecho, la Corona ya actuaba en este entonces para conseguir que en las Indias el señor de cada individuo fuera solo y siempre el rey, para que en aquellos territorios su potestas fuera libre y absoluta (Bartolomé Yun 2015:37; Bravo Lira 1986:70). Y esto explica por qué los conquistadores por sus grandes empresas "no esperaban una ayuda económica de su soberano y señor, pero sí el reconocimiento jurídico de sus posesiones y todavía más, su confirmación heráldica" (Lafave 1999:36), la Corona siempre frustró sus esperanzas. De hecho, si bien los aventureros ibéricos habían "salido al asalto del Nuevo Mundo para ganar ahí la posición en la riqueza y los honores que la Reconquista había procurado a sus mayores, y que el fin de esta, la toma de Granada, en 1492, les impedía esperar a su vez en la propia España", muy pronto debieron comprender que resultaba bastante improbable la concretización de su sueño americano (Lafave 1999:36). La Corona, es bien repetirlo, no tenía ninguna intención de "apoyar la tentativa de los hidalgos españoles de revivir en América la sociedad feudal, moribunda en la Península" (Lafave 1999:37). Todo lo contrario:

\begin{abstract}
una vez rotas las comunidades en Castilla, Carlos V siguió deseoso de imponer su poder absoluto a la nobleza, de domesticar a la grandeza y de limitar los fueros de los hidalgos. Así, pues, no vio sin inquietud la creación de nuevos feudos más allá de los mares -feudos de hecho, si no de derechogobernados por señores de fecha reciente y tanto más celosos de su independencia por cuanto se sentían creadores del país (Lafave 1999:36-37) ${ }^{25}$.
\end{abstract}

Sin embargo, es claro que todas las ventajas proporcionadas por los donativos voluntarios serían menores si los mismos se volvieran forzosos, ya que de esta manera el acto voluntario se convertía en una prueba de obediencia; y como tal ponía a la Corona en una incómoda posición respecto de los conquistadores, quienes, gracias a los servicios 
otorgados habrían podido incrementar su peso político, hasta entonces bastante mínimo. Carlos $\mathrm{V}$ no podía permitir que se asentara el precedente porque de ser así habría puesto a los conquistadores peruanos en condición de negociar con la Corona, según las mismas lógicas estamentales que tantos problemas le estaban causando en la Península ${ }^{26}$. Además, el emperador debía ser consciente que, antes o después, la formación de la costumbre habría legitimado a los peruanos a reclamar, entre otras cosas, la perpetuidad de las encomiendas y las prerrogativas feudales respecto de las mismas, que tanto bramaban para perfeccionar su posición jurídica e institucionalmente. De hecho, es necesario recordar que en el pensamiento teológico-jurídico medieval la costumbre se configuraba como tacitas voluntas principis, y su validez jurídica comenzó a depender únicamente del reconocimiento del poder político (Ramos 1999:287). No ha de extrañar, entonces, que al enterarse que muy probablemente los Pizarro se habían excedido en la recaudación del donativo, Carlos V intentó de inmediato enmendar el error: con cédula real, fechada 16 de diciembre de 1640, el emperador mandó al gobernador Cristóbal Vaca de Castro "llamar a todos los vasallos, que decían haber sido agraviados y forzados en él [servicio gracioso], que se le encargó y ejecutó a Hernando Pizarro", para que, en presencia de los Oficiales Reales, averiguase cómo efectivamente había pasado, "y remitiese el proceso al Consejo, para que hiciese justicia" (Gaspar de Escalona 1775:111).

A la fecha, aún no se pudo comprobar si efectivamente Vaca de Castro llevó a cabo la pesquisa que se le encomendó, o si la documentación requerida por la corte llegó en algún momento sobre la mesa del Consejo de Indias. Sin embargo, el solo hecho que desde España se advirtió la necesidad de encargarle la misión, demuestra que la Corona hasta un principio operó y vigiló para que los donativos solicitados a los vasallos americanos mantuviesen un carácter voluntario; y esto porque, como se ha dicho, solo así el soberano habría podido recaudar dinero sin tener que pagar un caro "gasto político" a las jóvenes élites americanas. Es decir, hasta un principio, la Corona quiso establecer en los territorios indianos una clara praxis institucional de recaudación extraordinaria, fundamentada en el recurso de donativos voluntarios, y, por tanto, gratuitos.

De otro modo, por ejemplo, no se entendería por qué Felipe II en ocasión de su ascenso al trono, al solicitar un nuevo donativo a los vasallos novohispanos especificó que el mismo habría de ser voluntario; recomendó que se dirigiera únicamente a las "personas que tuvieren comodidad y posibilidad"; mandó que durante las operaciones de recaudación no se hiciera a nadie "premia ni torcedor"27; algunos años después, para resanar el Real Patrimonio, dispuso que en las Indias se pedirían donativos voluntarios (León Pinelo 1630:117v); y, como habrá ocasión de decir en las próximas páginas, si bien muy sintéticamente, por obvias razones de espacio, los donativos que se pidieron en Perú durante su reinado, en 1574 y 1589, mantuvieron un claro carácter voluntario.

Acerca de estos dos donativos, a la fecha no mucho ha sido escrito. Respecto del donativo de 1574, por ejemplo, sabemos que sirvió para recaudar recursos para la defensa de la religión cristiana, amenazada por los turcos en el Mediterráneo y por los protestantes en Europa; que su recaudación, encomendada al virrey de Perú, Francisco Álvarez de Toledo y Figueroa, permitió reunir alrededor de 400.000 pesos (Pinto Vallejos 1980; Apuntes Históricos 1902; Odriozola 1877); y que la misma se llevó a cabo seguramente en las ciudades de Lima, Cuzco, Arequipa, La Paz, Potosí, entre otras (Pito Vallejos 1980:75). Además, algunos acontecimientos relatados por las fuentes permiten asumir que el servicio siempre mantuvo un carácter voluntario. En primer lugar, al momento de solicitarlo, Felipe II para poner en condición el virrey de explicar la difícil situación, y convencerlo a contribuir con un "señalado gracioso servicio", relató en una real cédula la dramática coyuntura bélica que estaba viviendo la Monarquía (De Nardi 2018b:1562-1563). Es decir, como ya había hecho en el pasado su padre, le sugirió al virrey toda una serie de argumentaciones persuasivas útiles para conmover los ánimos de los vasallos, y, por no poderse valer de su autoridad, lo invitó a contribuir él mismo al servicio para provocar emulación en los demás. Además, una vez recolectado el donativo, se sintió obligado de enviar cédulas de agradecimiento a los vasallos que se distinguieron en el servicio, entre estos figuraron las mujeres de la ciudad de Arequipa: un trato que difícilmente les habría reservado si su contribución hubiera sido forzosa o debida a la coerción.

De lo que estamos diciendo, por ejemplo, nos da cuenta, entre otros, Manuel de Odriozola, que, en su Colección de Documentos Literarios del Perú, explica que Felipe II se opuso a las amenazas turca y protestante con todas sus fuerzas y determinación, 
"derramando con liberal mano sus tesoros, para sustentar contra aquel pagano grandes armadas, y contra las provincias que tenía este heresiarca envenenada con su secta poderosos ejércitos" (Odriozola 1877:X:39). Sin embargo, muy pronto el Real Patrimonio no pudo aguantar más los grandes costos que las guerras conllevaban y el soberano se vio obligado a pedir al virrey del Perú que despachara a todas las ciudades del reino su real cédula con la que solicitaba un servicio gracioso: una "diligencia que se hacía mayor por ser en causa tan superior como la de Dios Nuestro Señor y la defensa de la República" (Odriozola 1877:X:39). En Arequipa, el Cabildo convocó a "todos los vecinos a dar en aquella voluntaria contribución la más verdadera señal de su lealtad y su rendimiento". Congregados en las dependencias del Cabildo, los jueces y regidores fueron los primeros a contribuir con "considerables cantidades de oro y plata, dudándose [en medio de distinguirse y excederse en visarria] si daban más en contribuciones a su Rey, que en ejemplos a los ciudadanos" (Odriozola 1877:X:39). Después de ellos, tocó a "los nobles, que cuanto más exentos $\mathrm{y}$ privilegiados de pagar precisos tributos, tanto más obligados se juzgaron en derramarse en esta voluntaria oblación en magnificas oblaciones"; al pueblo, que "concurrió también al donativo en confusas tropas, y aunque unos median lo que median a sus fortunas, y otros a su liberalidad, fue desmedida la suma que ofreció" (Odriozola 1877:X:39); y, en fin, a las mujeres de la ciudad, que

no solo contribuyeron axcesivas cantidades en pesos, sino que despojándose de lo más apreciable a su sexo, por ser los adornos de la hermosura, se desprendieron joyas; arracadas, miramelindos, ayrones, brazaletes, y otras costosas alahajas, y de todas hicieron precioso donativo para el socorro de las indigencias de su Rey, y solo entre doce matronas que no serían las más magníficas, sino las más acomodadas, se sumó la considerable cantidad de más de treinta mil ducados (Odriozola 1887:X:39-40).

Todas estas demostraciones tuvieron un carácter voluntario por ser fruto de una campaña de sensibilización, centrada en la selección de argumentaciones persuasivas, orquestada desde la Península y llevada a cabo por los ministros españoles encargados del gobierno del virreinato, llamados, entre otras cosas, a suscitar emulación entre los demás, contribuyendo ellos mismos. De otro modo, no se podría explicar la necesidad de fundamentar la petición del servicio; la participación manifiesta de los jueces y ministros al donativo; y, como se anticipó, que Felipe II llegó a despachar una real cédula para agradecer a las mujeres de Arequipa que ofrecieron sus joyas "para nos servir con ellas y por no mostrarse menos liberales y celosas del servicio de Nuestro Señor y nuestro, a imitación de las matronas romanas que hicieron otro tanto por la defensa de su República" (Odriozola 1887:X:42).

Y si bien todavía no disponemos de investigaciones monográficas al respecto, es muy fácil imaginar que lo mismo pasó en ocasión del donativo de 1589 , recaudado en Perú durante el virreinato de García Hurtado de Mendoza, IV marqués de Cañete: uno de los más importantes servicios recolectados en las Indias, ya que permitió reunir el notable monto de 2.143.733 pesos (Campos Harriet 1969:139-140). De hecho, al momento de solicitarlo, Felipe II envió al marqués de Cañete una real cédula para justificar su petición y proporcionar a su representante todas las argumentaciones persuasivas necesarias para poner en marcha una campaña de sensibilización. En estos documentos el monarca relató que en Europa la religión católica se veía violada por herejes (los ingleses), los que, por ser "cismáticos detestables", "causaban horrores y espanto"; explicaba que por ser él "hijo de la santa madre iglesia le tocaba destruir aquellos monstruos", y que había sido el mismo Dios a encomendarle la misión, ya que "por ocultos juicios había permitido fracasase la poderosa escuadra española, a pesar de los humildes ruegos, oraciones, ayunos y limosnas practicadas para que en sus empresas fuesen feliz bajo la protección divina" (Mendiburo 1933:IV:304). Es decir, el Señor había permitido la destrucción de la grande armada para obligarlo "a proseguir la lucha de que dependía el bien universal de la cristiandad y otros fines de importancia" (304). Sin embargo, por encontrarse sus rentas y patrimonio tan exhaustos, se veía obligado a "valerse de sus reinos y pedir a sus buenos y leales vasallos habitantes y naturales de las Indias, acudiesen a llenar la necesidad de socorrerle con el amor que le debían como a su rey y señor que tanto los estimaba, y con la misma decisión que otras veces lo habían hecho" (304-305). Por esta razón, mandaba a su virrey que invitara a contribuir "a los prelados, estado eclesiástico, ciudades, pueblos, encomenderos, personas particulares, tratantes, 
caciques e indios", pues, y esto es muy importante porque demuestra la elección de argumentaciones persuasivas, "todos necesitaban de seguridad en sus haciendas y comercio, exterminando a los herejes piratas cuyo castigo era una de las causas que más excitaban su ánimo" (305). Y como ya en los donativos precedentes, se preocupó de aclarar que el servicio habría tenido que ser gracioso, es decir, libre y gratuito (305). Parece claro que, como observó también Manuel de Mendiburu, ya en 1933, el lenguaje de la cédula "fue muy escogido", como muy bien pensados fueron los "estímulos y móviles usados en ella para causar impresión favorable y conseguir el fin propuesto" (305). Esto porque por ser el donativo de 1589 voluntario, "los ministros y oficiales podían decidir si pedir el servicio en su jurisdicción, y los vasallos eran libres de no contribuir" (De Nardi 2018b:1591-1592). Así que la cédula era redactada tanto para evitar que los ministros encargados de la recaudación se excusaran de llevarla a cabo, por ejemplo, argumentando que el virreinato se encontraba en una difícil situación económica, tanto para facilitar la acción de los recaudadores, que, por no poderse valer de su autoridad, habrían tenido que poner en acto una campaña de sensibilización y convencimiento. Por esta razón, el soberano al momento de solicitar el servicio proporcionaba varias argumentaciones persuasivas que habrían podido utilizarse para conmocionar a los vasallos y hacerles entender que, si bien vivían en las Indias, a miles y miles de kilómetros de distancia de las guerras y de los herejes, era también su interés socorrerlo, ya que se estaba esforzando por salvaguardar sus haciendas y su bienestar físico y espiritual. Además, la naturaleza voluntaria parecería comprobarse por otros dos acontecimientos, que por obvias razones de espacio, únicamente se pueden solo mencionar: como ya en 1574 , las mujeres de Arequipa decidieron socorrer al rey con sus joyas, y esta vez recibieron un mensaje de agradecimiento de la virreina doña Teresa de Castro y de la Cueva (Mendiburo 1933:IV:305); en la Audiencia de Charcas, para preparar el terreno a la recaudación del donativo, los ministros no solo intentaron suscitar emulación socorriendo en primera persona al soberano, sino que redactaron un específico manifiesto para que la población pudiera enterarse de las grandes necesidades de la Monarquía y se animara a donar (Levillier 1922:III:82-89) ${ }^{28}$.

\section{Conclusiones}

La investigación llevada a cabo permitió averiguar que los Habsburgo solicitaron veinte donativos voluntarios a sus vasallos peruanos $(1534,1574$, $1589,1598,1621,1626,1631,1636,1640,1647$, $1654,1660,1665,1672,1678,1679,1684,1688$, $1689,1697)$, cuya recolección permitió reunir por lo menos 7.487.935 pesos. El primero de estos servicios fue solicitado por Carlos I, quien, en 1534, encargó su recaudación a Hernando Pizarro, para asentar en los territorios peruanos, como ya se había hecho dos años antes en los mexicanos, una clara praxis institucional de recaudación extraordinaria, fundamentada en el recurso a donativos voluntarios, y por tanto gratuitos. De hecho, como se intentó demostrar en estas páginas, los donativos, siempre y cuando voluntarios, permitían a la Corona pedir un socorro a los conquistadores peruanos sin tener que recompensarlos. Es decir, tener que conceder mercedes o prerrogativas jurisdiccionales, de matriz feudal, a cambio del apoyo proporcionado. Por esta razón, apenas Carlos V se enteró que muy probablemente los Pizarro se habían excedido en la recaudación del servicio que les había encomendado, intentó enmendar el error y Felipe II se demostró siempre muy atento a que los servicios pedidos durante su reinado mantuvieran un carácter voluntario, como demuestran las cédulas expedidas para solicitar el servicio de 1574 y aquel de 1589. 


\section{Referencias Citadas}

\section{Fuentes inéditas}

AGI, MÉXICO.

AGI, PANAMÁ

Biblioteca Universitaria de Sevilla

1590 Razón de los Ramos de Hacienda que S.M Tiene en el Reino del Perú, Papeles del Marqués del Risco Sobre Asuntos del Gobierno del Perú en los Primeros Años del Siglo XVII, Fondo Antiguo.

\section{Fuentes éditas}

Altolaguirre y Duvale, A.

1930 Colección de las Memorias o Relaciones que Escribieron los Virreyes del Perú Acerca del Estado en que Dejaban las Cosas Generales del Reino. Tomo II. Imprenta Mujeres Españolas, Madrid.

Altolaguirre y Duvale, A. y A. Bonilla y San Martín.

1924 Índice General de los Papeles del Consejo de Indias. Tomo III. Tip. de la "Revista de archivos, bibliotecas y museos", Madrid.

Anales del Cuzco, 1600-1700

1901 Imprenta del Estado, Lima.

Apuntes Históricos del Perú y Noticias Cronológicas del Cuzco 1902 Imprenta del Estado, Lima.

Ballivian y Róxas, V.

1872 Colección de Documentos Relativos a la Historia de Bolivia, Durante la Época Colonial. Tomo I. A. Franck, Paris.

Bermudez, J. M.

1903 Anales de la Catedral de Lima. 1534-1824. Imprenta del Estado, Lima.

Colección de Documentos Inéditos Relativos al Descubrimiento,

Conquista y Organización de las Antiguas Posesiones Españolas de Ultramar.

1924 Vol. XV. Tip. de la "Revista de Archivos, bibliotecas y museos", Madrid.

Levillier, R.

1922 Audiencia de Charcas. Tomo III: Correspondencia de Presidentes y Oydores, Documentos del Archivo de Indias (1590-1600). Imprenta de Juan Pueyo, Madrid.

Levillier, R.

1926a Gobernantes del Perú, Cartas y Papeles, Siglo XVI, Documentos del Archivo de Indias. Tomo XIV: el Virrey Luis de Velasco (1596-1600). Imprenta de Juan Pueyo, Madrid.

Levillier, R.

1926b Papeles Eclesiásticos del Tucumán, Siglo XVII. Vol. I y II. Imprenta de Juan Pueyo, Madrid.

Memorias de los Virreyes que han Gobernado el Perú, Durante

el Tiempo del Coloniaje Español

1859 Tomo I. Librería Central de Felipe Bailly, Lima.

Montesinos, F.

1906 Anales del Perú. Publicado por Víctor M. Maurtua. Tomos I y II. Imprenta de Gabriel L. y del Horno, Madrid. Odriozola, $\mathrm{M}$.

1863 Colección de Documentos Literarios del Perú. Tomo VII. Imprenta del Estado, Lima.

Odriozola, M.

1877. Colección de Documentos Literarios del Perú. Tomo $\mathrm{X}$. Imprenta del Estado, Lima.
Relaciones de los Vireyes y Audiencias que han Gobernado el Perú. Relaciones de De Velasco, Guadalcázar, Chinchón, Alba y Audiencia

1871 Tomo II. Imprenta y Estereotipia de M. Rivadenetra, Madrid.

Toribio Polo, J.

1896 Memorias de los Virreyes de Perú. Marqués de Mancera y Conde de Salvatierra. Imprenta del Estado, Lima.

Torres de Mendoza, L.

1866-1867 Colección de Documentos Inéditos del Archivo de Indias. Relativos al Descubrimiento, Conquista y Organización de las Antiguas Posesiones Españolas de América y Oceanía, sacados de los Archivos del Reino, y muy Especialmente del de Indias. Tomos VI y VIII. Imprenta de Frias y compañia, Misericordia, Madrid.

\section{Referencias Bibliográficas}

Alarcón Olivos, M.

2017 "Los libros de cabildo y la temprana historia política del Perú colonial”. Histórica XLI: 145-168.

Arzáns de Orsúa y Vela, B.

1965 [1700] Historia de la Villa Imperial de Potosí, editado por H. Lewis y G. Mendoza. Tomos I y II. Brown University Press, Providence.

Ascione, I.

2015 "Documenti inediti per la storia di Hernan Cortes e della conquista del Messico, conservati nell' Archivio di Stato di Napoli”. En Burocracia, Poder Político y Justicia. Libro-Homenaje de Amigos del Profesor José María García Marín, editado por M. Torres Aguilar, pp. 127-156. Dykinson, Madrid.

Bakewell, P.

1989 "La maduración del gobierno del Perú en la década de 1560”. Historia Mexicana 39: 41-70.

Bravo Lira, B.

1986 Historia de las Instituciones Políticas de Chile e Hispanoamérica. Editorial Andrés Bello, Santiago de Chile.

Campos Harriet, F.

1969 Don García Hurtado de Mendoza en la Historia Americana. Editorial Andrés Bello, Santiago de Chile.

Ciaramitaro, F. y L. De Nardi.

2019 "Una alternativa a las asambleas estamentales para los territorios americanos: los donativos voluntarios entre economía y política (siglos XVI-XVII)". Mexican Studies 35: 300-326.

Dagnino, V.

1909 El Corregimento de Arica, 1535-1784. Imprenta de la Época, Arica.

De Nardi, L.

2018a "Los donativos voluntarios: un aspecto poco estudiado de la política americana de los Habsburgo de España (Siglos XVI-XVII)". América Latina en la Historia Económica 55: 7-35.

De Nardi, L.

2018b "El carácter voluntario de los donativos indianos entre praxis institucional y construcción del consenso (siglos XVI-XVII)”. Historia Mexicana 268: 1535-1598.

De Nardi, L.

2020 "Nuevos aportes sobre la recaudación del donativo voluntario de 1654 en el Virreinato del Perú. El caso de 
los corregimientos de Vilcas, Huanta y Castrovirreyna". En Donativos, Préstamos y Negociación, Siglos XVII a XIX. Fiscalidad Extraordinaria en la Monarquía Hispana, editado por G. del Valle Pavón. Instituto Mora, México.

Del Carmen Martín Rubio, M.

2014 Francisco Pizarro. El Hombre Desconocido. Ediciones Nobel, Oviedo.

Domínguez Ortiz, A.

1960 Política y Hacienda de Felipe IV. Editorial de Derecho Financiero, Madrid.

Domínguez Ortiz, A.

1985 "La desigualdad contributiva en Castilla durante el siglo XVII". En Instituciones y Sociedad en la España de los Austrias, editado por A. Domínguez Ortiz, pp. 97-145. Ariel, Barcelona.

Escalona, G.

1775 Gazophilacium Regium Perubicum. Libro I. Imprenta Blasi Roman.

Escobedo Mansilla, R.

1992 "Primeros años de la Real Hacienda del Perú". Actas (Ponencias y Comunicaciones) Congreso de Historia del Descubrimiento (1492-1556). Tomo IV: 11-34. Real Academia de la Historia-Confederación Española de Cajas de Ahorros, Madrid.

Fernández Álvarez, M.

1999 Carlos V, el César y el Hombre. Espasa-Calpe, Madrid.

Fortea Pérez, J. I.

2000 "Los donativos en la política fiscal de los Austrias (1625-1637): ¿servicio o beneficio?”. En Pensamiento y política económica en la época moderna, editado por L. A. Ribot García, L. De Rosa, y C. Belloso Martín, pp. 31-76. Editorial Actas, Madrid.

Fortea Pérez, J. I.

2003 Doctrinas y prácticas fiscales. Balance de la Historiografía Modernista: 1973-2001: Actas del VI Coloquio de Metodología Histórica Aplicada (Homenaje al Profesor Antonio Eiras Roel), editado por D. González Lopo y R. J. López López, pp. 489-513. Xunta de Galicia, Santiago de Compostela.

Fortea Pérez, J. I.

2008 "Négocier la nécessité: roi, royaume et fisc en Castille au temps des Habsbourg". En Les finances royales dans la monarchie espagnole (XVIe-XIXe siècles), editado por A. Dubet, pp. 259-275. Press Universitarie de Rennes, Rennes.

Fortea Pérez, J. I.

2011 "El Donativo de 1625 en el realengo andaluz". En Hacer Historia desde Simancas. Homenaje a José Luis Rodríguez de Diego, editado por A. Marcos Martín, pp. 317-338. Junta de Castilla y León, Valladolid.

Gelabert González, J. E.

1997 La Bolsa del Rey: Rey, Reino y Fisco en Castilla (15981648). Grijalbo, Barcelona.

Gil Martínez, F.

2015 De la negociación a la coerción: la recaudación del donativo de 1635. Studia Histórica: Historia Moderna 37: 211-234.

Herrera y Tordesillas, A.

1725-1730 Historia General de los Hechos de los Castellanos en las Islas y Tierra Firme del Mar Océano. Imprenta Real de Nicolás Rodríguez Franco, Madrid.
Iglesias, L.

2014 "Moros en la costa (del Pacífico). Imágenes e ideas sobre el musulmán en el virreinato del Perú". Diálogo Andino 45: 5-15.

Jiménez Jiménez, I.

2016 "Economía y urgencia fiscal: los asientos hacendísticos del Consulado de Lima en la segunda mitad del siglo XVII". Histórica 40: 35-63.

Lafave, J.

1999 Los Conquistadores: Figuras y Escrituras. Fondo de Cultura Económica, México.

Lanza García, R.

2008 "El donativo de 1629 en el distrito de Fernando Ramírez Fariñas". IX Congreso Internacional de la Asociación Española de Historia Económica, pp. 1-37. AEHE, Murcia. Lanza García, R.

2010a "El donativo de 1629 en la Andalucía Bética". Studia Histórica: Historia Moderna 32: 179-227.

Lanza García, R.

2010b "El donativo de las guerras de Italia (1629): estudio del caso del Arzobispado de Toledo y la provincia de Guadalajara". Obradoiro de Historia Moderna 19: 125-159.

Lavallé, B.

1977 Quito y la Crisis de la Alcabala (1580-1600). Institut Français d'Études Andines-Corporación Editora Nacional, Lima.

León Pinelo, A.

1922 Tratado de Confirmaciones Reales. Tomo I. Talleres S. A. Casa Jacobo Peusen, Buenos Aires.

Lohmann Villena, G.

1986 Francisco Pizarro. Testimonio. Documentos Oficiales, Cartas y Escritos Varios. Consejo Superior de Investigaciones Científicas, Madrid.

Lorente, $\mathrm{S}$.

1870 Historia del Perú Bajo la Dinastía Austriaca. 1598 1700. Imprenta de A. E. Rochette, París.

Marsilli, M. N.

2014. Hábitos Perniciosos: Religión Andina Colonial en la Diócesis de Arequipa (Siglos XVI al XVIII). Dirección de Bibliotecas, Archivos y Museos, Santiago de Chile.

Mendiburu, M.

1885 Diccionario Histórico Biográfico del Perú. Tomo V. Imprenta Bolognesi, Lima.

Mendiburu, M.

1933 Diccionario Histórico Biográfico del Perú. Tomos II, IV y VI. Imprenta de Estado, Lima.

Millones Santa Gadea, L.

2012 "Ensayo comparativo entre las conquistas de los estados precolombinos de México y Perú". Diálogo Andino 40: 5-14.

Montoya, R.

2013 La Sangre del Sol: Crónicas del Oro y la Plata que España Sacó de América. Vision Libros, Madrid.

Morrone, A. J.

2016 "No todos los caciques fueron mallku: mediación política truncada en los corregimientos de Pacajes y Omasuyos (Audiencia de Charcas, 1570-1630)". Diálogo andino 50: 207-217.

Pinto Vallejos, S.

1980 "Aportes extraordinarios a la Real hacienda española en el virreinato peruano: la región de Cuzco, 1575-1600". 
Jahrbuch für Geschichte Lateinamerikas (Anuario de Historia de América Latina) 17: 69-95.

Quintana y Lorenzo, M. J.

1922 Vidas de los Españoles Célebres. Tomo III. Calpe, Madrid. http://www.cervantesvirtual.com/obra-visor/ vidas-de-los-espanoles-celebres--0/html/fee59b24-82b111df-acc7-002185ce6064.html (3 marzo 2020).

Ramos, C.

1999 "Consideración de la costumbre en la doctrina jurídica virreinal. De la valoración clásica a su impugnación moderna”. En La Tradición Clásica en el Perú Virreinal, editado por T. Hampe, pp. 285-308. Sociedad Peruana Estudios Clásicos-Universidad Nacional Mayor de San Marcos, Lima.

Real Academia de la Historia.

2018 Liñán y Cisneros, Melchor de. Conde de la Puebla de los Valles. http://dbe.rah.es/biografias/12089/melchorlinan-y-cisneros (3 marzo 2020).

Rojo Vega, A.

2007 Datos Sobre América en los Protocolos de Valladolid: Siglos XVI-XVIII. Ayuntamiento de Valladolid, Valladolid.

Rosas Moscoso, F.

1990 "Civilización andina y conquista española: nuevas perspectivas en un antiguo debate". Diálogo Andino 9: 60-71

Suárez de Figueroa, C.

1613 Hechos de don García Hurtado de Mendoza. Imprenta real, Madrid.

Truchuelo García, S.

2008 "Privilegios y libertades fiscales: los donativos al monarca en los territorios vascos y Cataluña en el período alto moderno". Pedralbes: Revista d'Historia Moderna 28: 283-300.

Truchuelo García, S.

2010 "Donativos y exenciones: en torno a los servicios monetarios de las provincias vascas en el siglo XVII". Estudis: Revista de Historia Moderna 36: 189-211.

Valle Pavón, G.

1997 El Consulado de Comerciantes de la Ciudad de México y las Finanzas Novohispanas, 1592-1827. Tesis doctoral, Centro de Estudios Históricos-El Colegio de México, México.

Valle Pavón, G.

2016 Donativos, Préstamos y Privilegios. Los Mercaderes y Mineros de la Ciudad de México Durante la Guerra Anglo-española de 1779-1783. Instituto Mora, México.

Villanueva Urteaga, $\mathrm{H}$.

1959 Nuevos Datos Sobre la Vida y Obra del Obispo Mollinedo. Princeton Theological Seminary Library, Cuzco.

Yun Casalilla, B.

2002 La Gestión del Poder. Corona y Economías Aristocráticas en Castilla (Siglos XVI-XVIII). Akal, Madrid.

Yun Casalilla, B.

2004 Marte Contra Minerva. El Precio del Imperio Español, 1450-1600. Crítica, Barcelona.

Yun Casalilla, B.

2015 "Imperio español, entre la monarquía compuesta y el colonialismo mercantil". En La Fiscalidad Novohispana en el Imperio Español. Conceptualizaciones, Proyectos y Contradicciones, editado por M. P. Martínez, E. Sánchez y M. Souto, pp. 29-68. Instituto Mora-Universidad Nacional Autónoma de México, México.
$1 \quad$ De Nardi 2020; Ciaramitaro e De Nardi 2019; De Nardi 2018a; De Nardi 2018b; Del Valle Pavón 2016:19; Jiménez Jiménez 2016:38-39; Del Valle Pavón 1997:33-35; Pinto Vallejos 1980; Domínguez 1960:297-314.

2 De hecho, hay solo dos investigaciones: De Nardi 2020 y Pinto Vallejos 1980.

3 Gil Martínez 2015:211-234; Fortea Pérez 2011:317-338; Lanza García 2010a:179-227; Lanza García 2010b:125-159; Truchuelo García 2010; Lanza García 2008:1-37; Fortea Pérez 2008:259-275; Truchuelo García 2008:283-299; Fortea Pérez 2003:489-513; Fortea Pérez 2000:31-74; Gelabert González 1997:222-226; Domínguez Ortiz 1985:97-145; Domínguez Ortiz 1960:297-314.

4 Por ejemplo, en 2016, Ismael Jiménez Jiménez, estudiando la economía peruana en la segunda mitad del siglo XVII, definió los donativos como "solicitudes con un carácter más forzoso que voluntario" (2016:38).

5 Anteriormente, se pensaba que los primeros a pedir un donativo en las Indias habían sido los Austrias. De hecho, no fue posible encontrar alguna publicación que mencionara los servicios solicitados por los Reyes Católicos a los vasallos de La Española.

6 Como subrayado por Lucila Iglesias, la imagen amenazante de los turcos en las Indias, y en el virreinato del Perú, respondía "al traslado de una tipología que funcionaba en
España, y que en las Indias resultaría eficaz para señalar a un enemigo 'prototípico' del dogma católico" (2014:6).

7 Antes, se pensaba que los donativos pedidos por los Austrias en las Indias habían sido 23 (De Nardi 2018a:7-35). Sin embargo, nuevas investigaciones permitieron descubrir que Carlos V pidió tres donativos a sus vasallos indianos, y no solo uno como antes se creía, y que el donativo de 1608 no puede considerarse entre los voluntarios, ya que se dirigía únicamente a los comerciantes culpables de transportar mercancías en la flota sin declararlas.

8 Parece que, en 1520, Carlos V encargó el almirante don Diego Colón recaudar un donativo voluntario en la isla $\mathrm{La}$ Española. Sucesivamente, sin embargo, la orden se revocó a causa de la epidemia de viruela. Así que el servicio nunca se recolectó (Herrera y Tordesillas 1730:Década II:Libro IX:225).

9 Como se dirá más adelante, la investigación desarrollada para este artículo permitió averiguar que, en 1534, Carlos V aprovechó del viaje a España de Hernando Pizarro para pedirle que recaudara un servicio gracioso en su nombre entre los vecinos del Cuzco (Quintana y Lorenzo 1922:III:169-170; Rojo Vega 2007:487-488; Escobedo Mansilla 1992:IV:11-34; Mendiburu 1933:VI:460; Colección de Documentos 1924:XV:114; Montesinos 1906:I:88,99; Escalona 1775:111). 
10 Probablemente, a causa de la compleja situación política que estaba viviendo Perú, es plausible que este donativo haya sido solicitado solo en Nueva España. Para mayores detalles cerca de la coyuntura política e institucional peruana de aquellos años véase Bakewell 1989.

11 Antes se fechaba la petición del donativo en 1575. Sin embargo, la fecha de la cédula permitió adelantarlo al 1574 (Apuntes Históricos 1902:222).

12 Como se ha dicho no es claro si el donativo de 1556 fue solicitado también en Perú.

13 Se sabe que fue pedido en la Nueva España. Así que es fácil imaginar que lo mismo pasó también en Perú, si bien no se encontraron pruebas de esto (Archivo General de Indias (AGI), MÉXICO, 27, N. 72, Real Cédula. 14.04.1609).

14 Antes se fechaba la petición de este donativo en 1626. La revisión de la documentación permitió adelantarlo al 1526 (AGI, PANAMÁ, 18, R.1, N. 3, Real Cédula. Madrid, 9.01.1625).

15 Antes este donativo no se conocía. Se encontraron referencias a él en Villanueva Urteaga 1959:19.

16 No faltaron las excepciones: el servicio voluntario de 1640 se dirigió a los portugueses, el de 1672 al clero regular, y el de 1688 al estado eclesiástico (De Nardi 2018a:23).

17 Por ejemplo, en el virreinato del Perú, para el donativo de 1575 , los préstamos montaron a 128.969 pesos (Pinto Vallejos 1980:76); en 1589, Felipe II, preocupado que el donativo pedido por entonces en los territorios peruanos por el virrey no surtiera mucho efecto, envió una segunda cédula para precisar que si le hubieran prestado "las sumas mayores que fuera posibles les pagaría a los plazos que señalaran" (Mendiburu 1933:35). En la Nueva España los préstamos llegaron a 439.897 pesos en 1598 , y a 419.084 pesos en 1621 (De Nardi 2018a:23).

18 Por ejemplo, para el donativo de 1574 los vecinos de la ciudad de Cuzco y de su partido donaron 11,5 fanegas de chuño, 25 carneros de la tierra y 30 de Castilla, 9,5 fanegas de maíz y 6 cestos de coca (Pinto Vallejo 1980:80), mientras que las mujeres de la ciudad de Arequipa decidieron ofrecer sus joyas, cuyo valor se estimó en 30.000 pesos (Odriozola 1887:X:39-40). Para el de 1589 los vasallos peruanos, además de 2.092.985 pesos, donaron varias tipologías de bienes y mercaderías (Pinto Vallejo 1980:88). Además de ello, como ya se dijo en otras publicaciones, "desde Madrid se animaba a los ministros indianos a aceptar todo tipo de donaciones, para poder permitir a cualquier vasallo socorrer a su soberano". Por ejemplo, en 1621, el Consejo de Indias recordó al presidente de la Audiencia de Quito que "quien no pudiera contribuir con oro, plata, joyas o monedas, habría podido hacerlo con 'frutos de sus haciendas y otras cosas en especie', y que lo recaudado habría tenido que venderse 'con el mayor beneficio' de la real hacienda". No debe extrañar, entonces, que aun en 1635, en ocasión de donativo, la ciudad de Porto Viejo donó "17.300 manejos de tabaco", que se vendieron en el mercado de Lima por 3.000 pesos (De Nardi 2018a:19-23).

19 Al listado se añadieron los donativos de 1534 y 1684 , que antes no se conocían, mientras se quitaron los de 1556 y 1609 por no estar cierto que se recaudaron en Perú.

20 Las nuevas informaciones permiten actualizar los datos proporcionados por De Nardi 2018a. Para el donativo del 1534 véase: Rojo Vega 2007:487-488; Escobedo Mansilla
1992:IV:11-34; Mendiburu 1933:VI:460; Colección de Documentos 1924:XV:114; Quintana y Lorenzo 1922:III:169170; Montesinos 1906:I:88,99; Escalona 1775:111. Para el donativo de 1574: Pinto Vallejos 1980:73-82; Apuntes Históricos 1902:222-223; Odriozola 1877:X:37-43. Para el de 1589: De Nardi 2018a:13,21; Lavallé 1977:23,57,59; Campos Harriet 1969:139-140; Arzáns de Orsúa y Vela 1965:I:201; Mendiburu 1933:IV:304-305; Levillier 1922:III:82-93,95-107,178-179,181-183,404-407; Montesinos 1906:II:109; Apuntes Históricos 1902:239; Torres de Mendoza 1866-1867:VI:554-560;VIII:329-363; Suárez de Figueroa 1613:180-191; Biblioteca Universitaria de Sevilla 1590:s.h. Para el donativo de 1598: Colección de Documentos 1872:I:327; Montesinos 1906:II:148; Levillier 1922:III:415-417; Levillier 1926a: XIV:145,194-195,207209; Arzáns de Orsúa y Vela 1965:I:266. Para el donativo de 1621: De Nardi 2018a:13-14,21; Levillier 1926b:I:369370,422-424; Montesinos 1906:II:220-221; Anales del Cuzco 1901:49. Para el donativo de 1625: Altolaguirre y Duvale e Bonilla y San Martín 1924:III:90-9; Dagnino 1909:228-230; Anales del Cuzco 1901:57-58; Ballivian y Róxas 1872:I:382. Para el donativo de 1631: De Nardi 2018a:14, 21; Mendiburu 1933:II:105; Altolaguirre y Duvale e Bonilla y San Martín 1924:III:145; Anales del Cuzco 1901:72. Para el donativo de 1636: De Nardi 2018a:15,21; Marsilli 2014:66; Levillier 1926b:II:78-80; Anales del Cuzco 1901:74. Para el de 1640: Arzáns de Orsúa y Vela 1965:II:98; Altolaguirre y Duvale 1930:II:158-160; Toribio Polo 1896:27-28. Para el donativo de 1647: Altolaguirre y Duvale 1930:II:160; Toribio Polo 1896:28. Para el donativo de 1654: De Nardi 2018a:15,21; De Nardi 2020; Arzáns de Orsúa y Vela 1965:II:155; Bermudez 1903:106; Anales del Cuzco 1901:138; Relaciones de los Virreyes 1871:II:163. Para el de 1660: De Nardi 2018a:15,21; Mendiburu 1933:II:28; Relaciones de los Virreyes 1871:II:163-164; Odriozola 1863:VII:81. Para el donativo de 1665: Mendiburu 1933:II:33-34; Bermudez 1903:130; Anales del Cuzco 1901:149-150; Lorente 1870:181-182; Odriozola 1863:VII:84. Para el donativo de 1672: Arzáns de Orsúa y Vela 1965:II:267; Villanueva Urteaga 1959:14; Ballivian y Róxas 1872:I:382; Memorias de los Virreyes 1859:I:243,248. Para el donativo de 1678: Real Academia de la Historia 2018:Liñán y Cisneros. Para el donativo de 1679: Mendiburu 1885:V:21; Odriozola 1863:VII:92; Memorias de los Virreyes 1859:I:370-371. Para el de 1684: Villanueva Urteaga 1959:19. Para el donativo de 1688: Arzáns de Orsúa y Vela 1965:II:348; Villanueva Urteaga 1959:21. Para el donativo de 1689: De Nardi 2018a:16,21; Villanueva Urteaga 1959:22. Para el de 1697: Arzáns de Orsúa y Vela 1965:II:399; Anales del Cuzco 1901:193; Ballivian y Róxas 1872:I:479.

21 Al respecto véase Millones Santa Gadea 2012 y Rosas Moscosos 1990

22 Asimismo, como se observó en otra publicación, "ya desde 1519 las inmensas riquezas provenientes de las tierras americanas hicieron vislumbrar a Carlos V que, gracias a estos territorios, sería posible redimensionar su dependencia de los servicios ofrecidos por las Cortes" (Ciaramitaro e De Nardi 2019:47); y lo dicho es ahora aún más cierto, ya que, gracias a las nuevas informaciones que se reunieron para este artículo, se sabe que, en 1520, Carlos V intentó 
pedir un donativo en La Española (Herrera y Tordesillas 1730:Década II:Libro IX:225).

23 Es decir, a los Pizarro se le solicitó desempeñar un papel de intermediación política entre la Corona y los demás conquistadores peruanos no muy distinto a lo que más adelante habrían sido llamados a desempeñar los caciques locales hacia sus comunidades. Con el solo fin de ejemplo, al respecto véase Morrone 2016.

24 Se confirma lo observado por Yun Casalilla 2015. Respecto de las difíciles relaciones entre Carlos I, nobleza y comunidades castellanas consúltese Ciaramitaro e De Nardi 2019 y Fernández Álvarez 1999.

25 Claramente, hubo excepciones: Carlos V concedió a Cortés el título de marqués del Valle de Oaxaca más 23.000 vasallos en las tierras descubiertas en la Nueva España (Ascione 2015:150).

26 Como lo ha subrayado Yun Casalilla, "incluso la guerra y sus derivaciones fiscales, motivo siempre de problemas en las relaciones entre rey y reino, se habían afrontado de modo que el resultado sería una cooperación conflictiva que no llevaría a grandes convulsiones, y que queda muy lejos de los dos polos, el de la obediencia ciega y el de la resistencia y conflicto sistemáticos, que diferentes corrientes historiográficas han descrito hasta hoy" (Yun Casalilla 2004:561-62). Acerca del tema véase también Yun Casalilla 2002:105,160.

27 Las citaciones se extrapolaron de la carta que Felipe II escribió el 17 de junio de 1556, desde Bruselas, al virrey de México, para informarle de su ascenso al trono y pedirle que recolectara un donativo (Torres de Mendoza 1866-1867:III:140).

28 Es intención de quien escribe publicar un artículo de la recaudación del donativo de 1589 en la Audiencia de Charcas. 